Research Article

\title{
High Sensitive Sensor Fabricated by Reduced Graphene Oxide/Polyvinyl Butyral Nanofibers for Detecting Cu (II) in Water
}

\author{
Rui Ding, ${ }^{1}$ Zhimin Luo, ${ }^{2}$ Xiuling Ma, ${ }^{3}$ Xiaoping Fan, ${ }^{1}$ \\ Liqun Xue, ${ }^{4}$ Xiuzhu Lin, ${ }^{4}$ and Sheng $\mathrm{Chen}^{4}$ \\ ${ }^{1}$ College of Environmental Science and Engineering, Fujian Normal University, 8 Shangsan Road, Fuzhou 350007, China \\ ${ }^{2}$ Jiangsu Key Laboratory for Organic Electronics \& Information Displays and Institute of Advanced Materials (IAM), \\ Nanjing University of Posts and Telecommunications, Nanjing 210046, China \\ ${ }^{3}$ College of Chemistry and Chemical Engineering, Fujian Normal University, 8 Shangsan Road, Fuzhou 350007, China \\ ${ }^{4}$ Department of Biology and Chemistry Engineering, Fuqing Branch of Fujian Normal University, 1 Longjiang Road, \\ Fuqing 350300, China
}

Correspondence should be addressed to Zhimin Luo; iamzmluo@njupt.edu.cn and Sheng Chen; chensheng@fjnu.edu.cn

Received 28 September 2014; Revised 29 November 2014; Accepted 5 January 2015

Academic Editor: Giuseppe Spoto

Copyright (C) 2015 Rui Ding et al. This is an open access article distributed under the Creative Commons Attribution License, which permits unrestricted use, distribution, and reproduction in any medium, provided the original work is properly cited.

Graphene oxide (GO)/polyvinyl butyral (PVB) nanofibers were prepared by a simple electrospinning technique with PVB as matrix and $\mathrm{GO}$ as a functional nanomaterial. GO/PVB nanofibers on glassy carbon electrode (GCE) were reduced through electrochemical method to form reduced graphene oxide (RGO)/PVB nanofibers. The morphology and structure of GO/PVB nanofiber were studied by scanning election microscopy (SEM), transmission electron microscopy (TEM), and Fourier transform infrared (FTIR). RGO/PVB modified GCE was used for fabricating an electrochemical sensor for detecting Cu (II) in water. The analysis results showed that RGO/PVB modified GCE had good analytical results with the linear range of $0.06-2.2 \mu \mathrm{M}$, detection limit of $4.10 \mathrm{nM}$ $(S / N=3)$, and the sensitivity of $103.51 \mu \mathrm{A} \cdot \mu \mathrm{M}^{-1} \cdot \mathrm{cm}^{-2}$.

\section{Introduction}

With the development of the industrialization, more and more containments caused the serious environmental problems. Among these pollutants, heavy metals have attracted great attention for they are harmful to human beings due to their toxicity, cumulative and nobiodegradability. Copper is one of the essential elements for human beings, but excessive intake of this element can result in certain diseases like Wilson's disease and Menke's syndrome, and so forth [1]. However, the casual wastewater discharge from mining, machinery manufacturing, and metal smelting led to a serious copper pollution in water. Therefore, search for real-time, rapid, and sensitive detection of $\mathrm{Cu}$ (II) in water system is of significance. A variety of methods have been established to detect $\mathrm{Cu}$ (II), such as flame atomic absorption spectrometry [2], UV-vis spectrophotometry [3], and inductively coupled plasma mass spectrometry [4]. These traditional detection methods have achieved rather good detection limit. However, they need a tedious pretreatment or result in spectroscopic interference. On the contrary, the electrochemical methods [5-10] have been widely applied for detecting trace ions in water because they are sensitive, accurate, inexpensive, rapid, and portable. For example, a functionalized carbon nanotubes paste electrode (CNPE) modified with crosslinked chitosan was used for detecting $\mathrm{Cu}$ (II) with the limit detection of $10 \mathrm{nM}$ and the linear range of $0.079-16 \mu \mathrm{M}$ [11]. An electrochemical sensor based on the functionalized polypyrrole (PPy) nanotube modified with tripeptide (Gly-Gly-His) was developed for detecting $\mathrm{Cu}$ (II) with the detection limit of $46 \mathrm{nM}$ and the linear range of $0.1-30 \mu \mathrm{M}$ [12]. In order to improve the sensitivity and the analytical performance, new nanomaterials will be needed to construct the sensor for $\mathrm{Cu}$ (II) detection. 
Graphene, a single layer of $\mathrm{sp}^{2}$ bonded carbon atoms arranged into a honeycomb structure with extraordinary electronic transport properties, excellent electrocatalytic activities [13], high modulus, and high specific surface area $[14,15]$, has stimulated extensive attention since its discovery [16]. It has been applied in many technological fields, including photodetectors $[17,18]$, antibacterial materials $[19,20]$, fuel cells [21, 22], lithium ion batteries [23], and supercapacitors $[24,25]$, and has been developed as an advanced nanoelectrocatalyst for constructing electrochemical sensors $[26,27]$. The used graphene in electrochemistry was usually produced from the reduction of graphene oxide. However, reduced graphene oxides (RGO) tend to agglomerate during the reduction of graphene oxide (GO) because of the van der Waals and $\pi-\pi$ stacking interactions among individual graphene sheet interactions, which may reduce the conductivity and its specific surface area, and thus result in weakening the performance of sensor based on RGO $[28,29]$. Electrospinning is a simple and cost-effective technique to fabricate one-dimensional nanostructures with high surface area and porosity [30], such as the electrospinning carbon nanofiber, which has been a promising candidate for designing gas sensors [31], chemical sensors [32-34], and biosensors [35] due to its remarkable electronic properties, electrochemical performances, and mechanical strength [36]. Through electrospinning technique, the made RGO can avoid agglomerating.

In this study, a novel $\mathrm{Cu}$ (II) sensor was fabricated based on RGO/PVB nanofibers, which was prepared by electrospinning the composite of GO and PVB and in situ electrochemical reduction of GO/PVB nanofibers. The RGO/PVB nanofibers modified glassy carbon electrode (GCE) was used for $\mathrm{Cu}$ (II) detection by differential pulse anodic stripping voltammetry (DPASV). The as-fabricated sensor based on RGO/PVB nanofibers showed good analytical performance with the linear range of $0.06-2.2 \mu \mathrm{M}$, a low detection limit of $4.1 \mathrm{nM}(S / N=3)$, high sensitivity of $103.51 \mu \mathrm{A} \cdot \mu \mathrm{M}^{-1} \cdot \mathrm{cm}^{-2}$, good selectivity, and excellent reproducibility $(\mathrm{RSD}=0.49 \%)$.

\section{Materials and Methods}

2.1. Chemical Reagents. Sodium acetate and glacial acetic acid (99.5\%) were purchased from Guoyao Chemicals Co. Ltd. Nafion (5\%) was a product of Sigma-Aldrich. PVB (butyral content: 66\%-75\%), potassium hydroxide, and N,Ndimethylformamide were obtained from Guoyao Chemicals Co. Ltd. All the other reagents are of analytical grade. The used water was deionized water.

2.2. Preparation of $G O / P V B$ Nanofiber. The uniform electrospinning solutions were prepared by mixing GO, PVB, and N,N-dimethylformamide (DMF). DMF was used as a solvent. The solution was placed in a $5 \mathrm{~mL}$ syringe with a metallic needle of $0.4 \mathrm{~mm}$ of inner diameter. The syringe was fixed horizontally and connected with a high voltage power supply (Tianjin Technical Corp.), which could generate DC voltage up to $30 \mathrm{KV}$. The supplied voltages between the tip and collector were set at $16 \mathrm{KV}$ with a tip-to-collector distance of $15 \mathrm{~cm}$. After several minutes, PVB/GO nanofiber-modified GCE (GCE/PGNF) was prepared and dried at $60^{\circ} \mathrm{C}$ for next use.

2.3. Fabrication of RGO/PVB Modified GCE. GO/PVB nanofiber was fixed on GCE through dropping $3 \mu \mathrm{L} 0.5 \%$ Nafion on the surface of GCE/PGNF. Then GCE/PGNF was immersed into the $0.1 \mathrm{M} \mathrm{KOH}$ solution and reduced by scanning cyclic voltammetry with the $\mathrm{Pt}$ wire as counter electrode and $\mathrm{Ag} / \mathrm{AgCl}$ (saturated by $\mathrm{KCl}$ ) as reference electrode. The formed GCE modified with RGO/PVB nanofiber (GCE/PRGNF) was washed with deionized water and stored for $\mathrm{Cu}$ (II) detection.

\subsection{Detection of $\mathrm{Cu}$ (II) with GCE/PRGNF. GCE/PRGNF} was immersed into HAc-NaAc buffer solution ( $\mathrm{pH} 4.4)$ with various concentrations of copper ions for several minutes, the electrochemical response was measured by DPASV with a scanning potential range from -0.6 to $0.6 \mathrm{~V}$, a step voltage of $4 \mathrm{mV}$, an impulse amplitude of $50 \mathrm{mV}$, a pulse width of $0.06 \mathrm{~s}$, and a pulse separation of $0.20 \mathrm{~s}$, and the GCE/PRGNF was accumulated for $270 \mathrm{~s}$ with stirring under the constant potential of $-0.5 \mathrm{~V}$. The setup of the process used in the study is shown in Figure 1. After each DPASV measurement, the electrode was rinsed by i-t method at $0.60 \mathrm{~V}$, placed in blank solution for $30 \mathrm{~s}$ for removing the sediment that adsorbed on the surface of the electrode and restoring the catalytic activity of the electrode. All the experiments were conducted at room temperature without deoxygenization. Nanofibers without GO or RGO were used for control experiments under the same condition.

\section{Results and Discussion}

3.1. Characterization of GO/PVB Nanofibers. The morphologies of the GO/PVB nanofibers were observed by scanning electron microscopy (SEM). GO/PVB nanofibers prepared with different concentrations of GO $(0.8125 \%, 1.625 \%, 3.25 \%$, $4.875 \%, 5.25 \%$, and $6.875 \%$ ) were explored. As shown in Figure 2, PVB/GO nanofiber $(0.8125 \%$ GO) (Figure $2(\mathrm{a})$ ) showed more uniform morphology of fibers. With the increase of the mass ratio of GO, the nanofibers became rather rough (Figure 2(b)), or even reunited (Figure 2(f)), because GO was over the solubility limit of DMF. Compared with Figure 2(g), the nanofibers did not change (Figure 2(h)) after stirring in water as PVB was nonhydrophilic. The representative TEM images of the GO/PVB nanofibers showed that GO was relatively dispersed in the nanofibers without any agglomeration.

Figure 3 showed the FTIR spectra of PVB nanofibers (Figure 3(a)) and PVB/GO nanofibers (Figure 3(b)). Compared with the spectrum of PVB nanofibers, the spectrum of $\mathrm{PVB} / \mathrm{GO}$ nanofibers showed the intense absorption at $1628 \mathrm{~cm}^{-1}$ and $3400 \mathrm{~cm}^{-1} .1628 \mathrm{~cm}^{-1}$ can be assigned to the stretching vibration of epoxy group and carbon frame of GO. $3400 \mathrm{~cm}^{-1}$ corresponds to stretching vibration of hydroxy of GO. FTIR characterization confirms the dispersion of GO on the PVB matrix. 


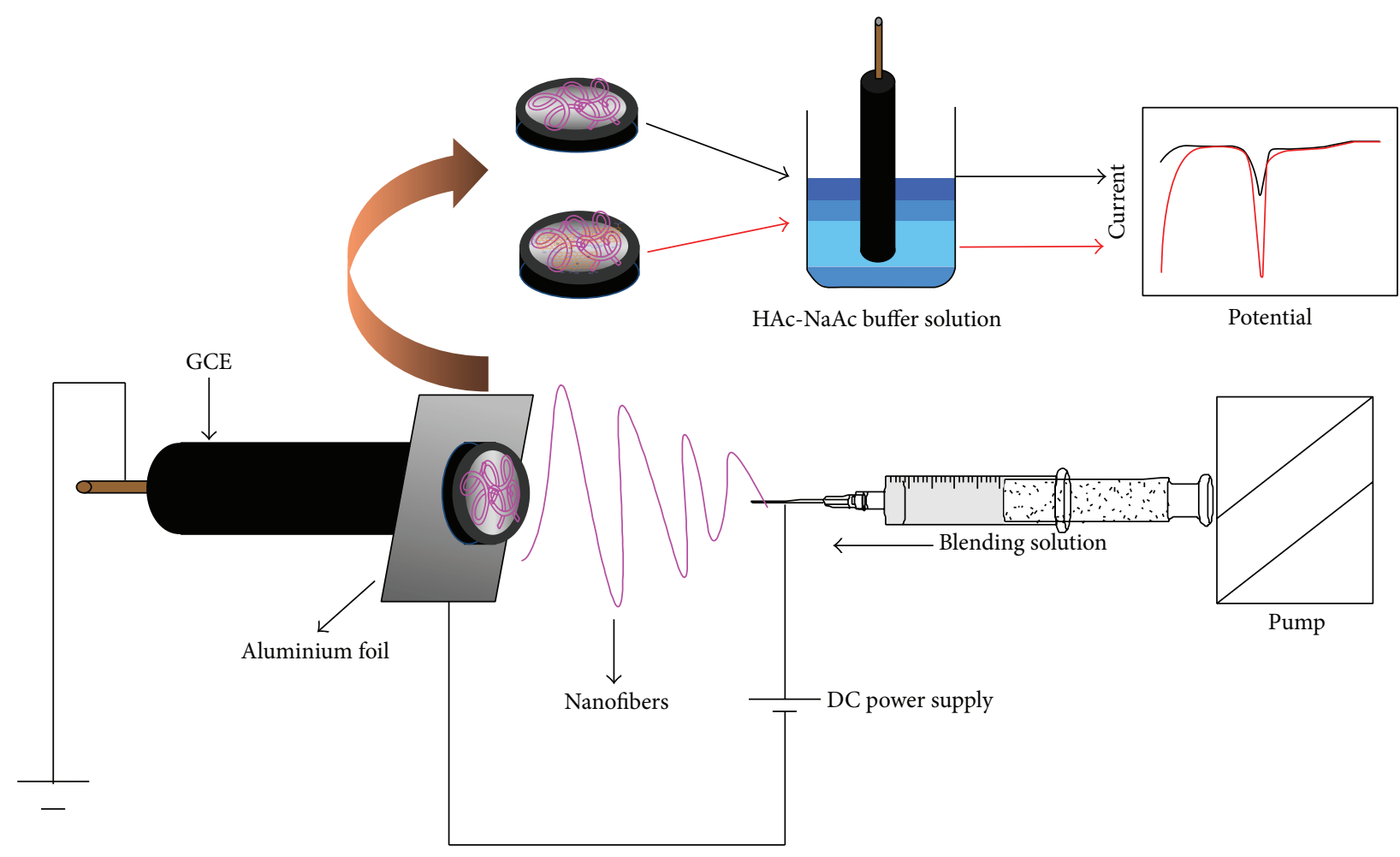

PVB nanofibers

GO

FIGURE 1: Schematic illustration of electrospinning device.

3.2. Electrochemical Detection of $\mathrm{Cu}$ (II) with GCE/PRGNF. Bare GCE, GCE/PVB, and GCE/PRGNF were used for detecting $\mathrm{Cu}$ (II) by DPASV. The measurements were carried out using a solution with $6.0 \times 10^{-7} \mathrm{~mol} \cdot \mathrm{L}^{-1}$ of $\mathrm{Cu}$ (II) in $0.1 \mathrm{~mol} \cdot \mathrm{L}^{-1}$ of NaAc-HAc ( $\mathrm{pH} 4.4$ ), the accumulation potential range from -0.6 to $0.6 \mathrm{~V}$, and accumulation time of $270 \mathrm{~s}$. As shown in Figure 4, the anodic peak current response of the GCE/PRGNF (Figure 4(c)) was $5.9 \mu \mathrm{A}$, which is higher than bare GCE (Figure 4(a)) $(2.8 \mu \mathrm{A})$ and GCE/PVB (Figure 4(b)) $(3.0 \mu \mathrm{A})$, indicating that RGO/PVB nanofiber can improve electroanalytical responses for $\mathrm{Cu}$ (II). It can be explained by two beneficial factors. One is the high conductivity of RGO in $\mathrm{RGO} / \mathrm{PVB}$ nanofibers, which promotes the electron transfer in the procedure of detection. The other is the active sites of RGO in RGO/PVB nanofibers, which can absorb $\mathrm{Cu}$ (II) for increasing the amount of electrochemical reaction and enhance the current response for detecting $\mathrm{Cu}$ (II).

3.3. Optimization of Detection Conditions. The influences of detection conditions such as $\mathrm{pH}$, accumulation potential, accumulation time, and electrospinning time were investigated. As can be seen in Figures 5(a) and 5(b), GCE/PRGNF had the best performance when the $\mathrm{pH}$ was 4.4 and the potential was $-0.5 \mathrm{~V}$. Therefore, $0.1 \mathrm{~mol} \cdot \mathrm{L}^{-1}$ of $\mathrm{NaAc}-\mathrm{HAc}$ ( $\mathrm{pH}$ 4.4) was selected for the best supporting electrolytes and $-0.5 \mathrm{~V}$ was chosen for next experiments.

Figure 5(c) displayed the influence of accumulation time for stripping peak currents. With the increase of accumulation time, the stripping peak currents increased and reached to the maximum value after $270 \mathrm{~s}$.

The electrospinning time was studied in the range of 212 s. As shown in Figure 5(d), when the electrospinning time was $8 \mathrm{~s}$, the response current was highest since there was not enough PVB/RGO nanofiber on the surface of GCE when the electrospinning time was too short. If electrospinning time was too long, there was too much PVB/RGO, which influenced the transfer of electron on the surface of the modified GCE.

3.4. Reproducibility of GCE/PRGNF. The repeated use of GCE/PRGNF was examined by the i-t measurement of detecting $\mathrm{Cu}$ (II). Table 1 showed the change of peak currents after 10 determinations of $6.0 \times 10^{-7} \mathrm{~mol} \cdot \mathrm{L}^{-1} \mathrm{Cu}$ (II) using the same GCE/PRGNF. The relative standard deviation was $0.49 \%$, indicating that the GCE/PRGNF has an excellent repeated performance for sensing $\mathrm{Cu}$ (II). 


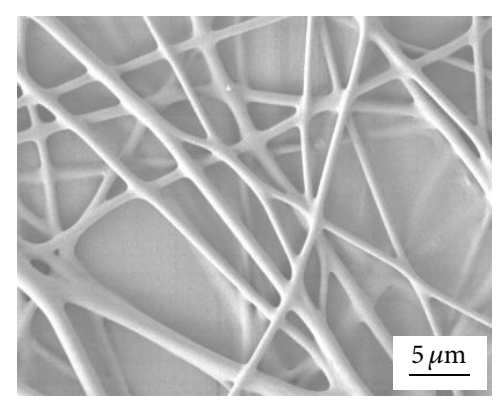

(a)

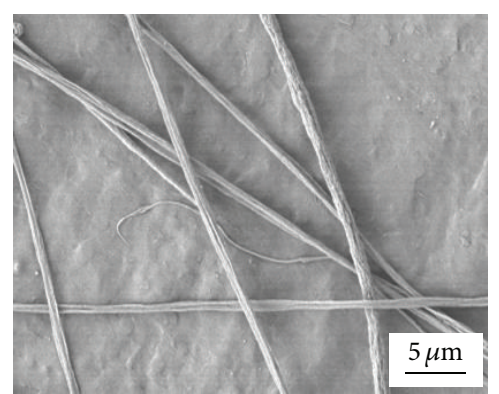

(d)

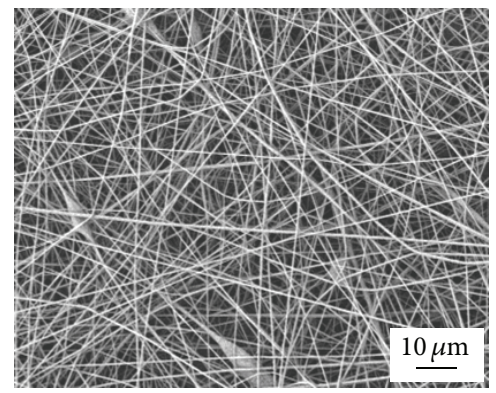

(g)

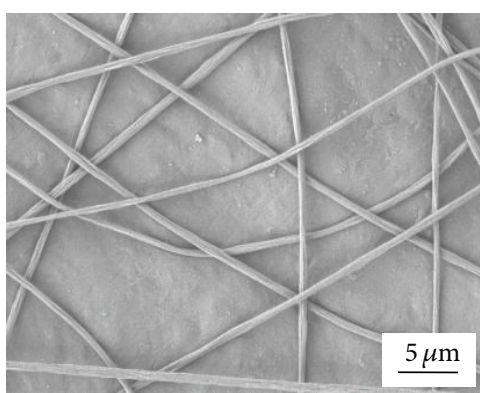

(b)

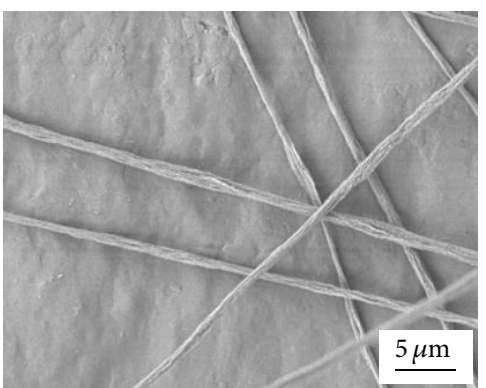

(e)

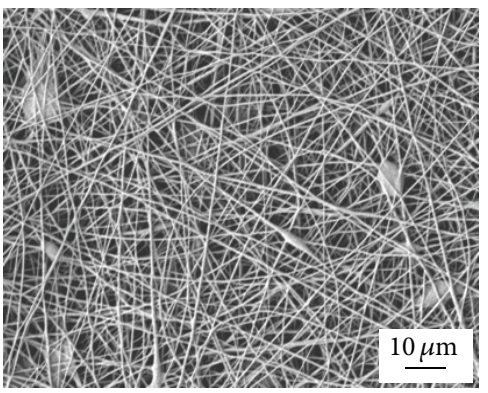

(h)

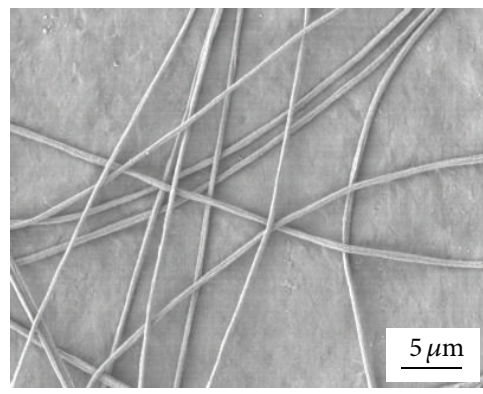

(c)

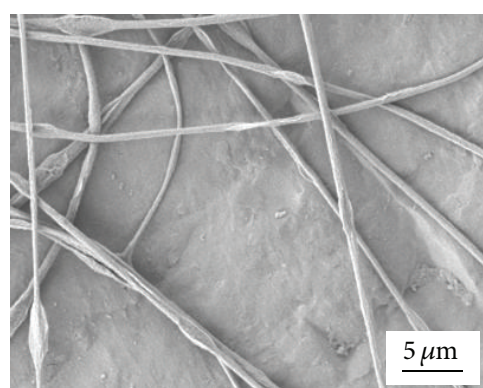

(f)

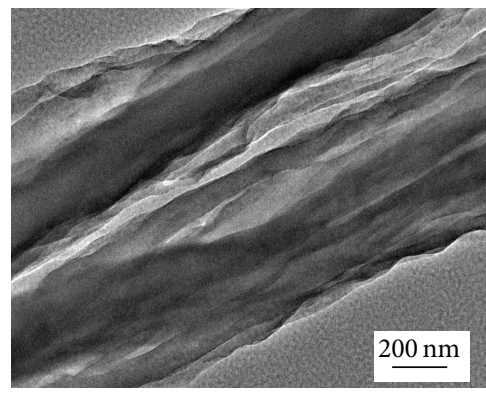

(i)

Figure 2: ((a)-(f)) SEM images of electrospun GO/PVB nanofibers ((a) 0.8125\%; (b) 1.625\%; (c) 3.25\%; (d) 4.875\%; (e) 5.25\%; (f) 6.875\% GO); SEM images of electrospun GO/PVB nanofibers (g) before and (h) after the oscillation in water for 5 h; (i) TEM image of GO/PVB fiber.

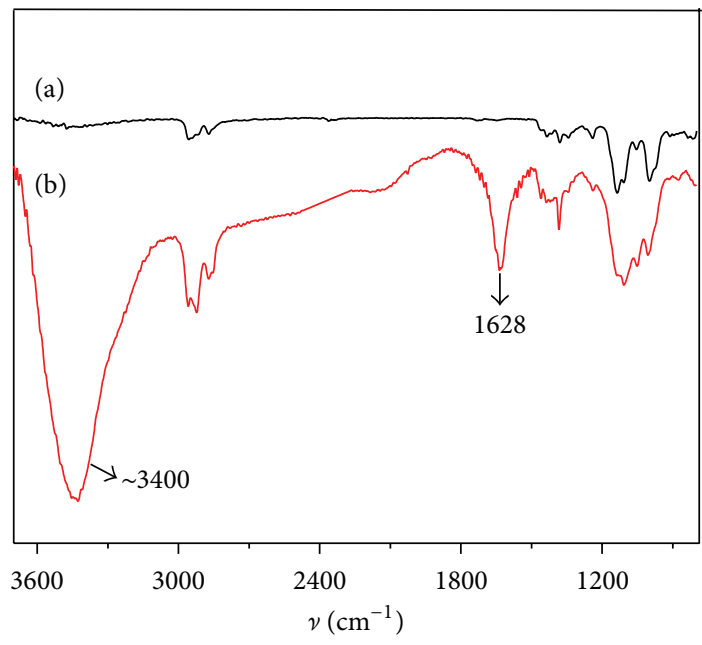

FIGURE 3: FTIR spectra of PVB (a) and GO/PVB (b) nanofibers.

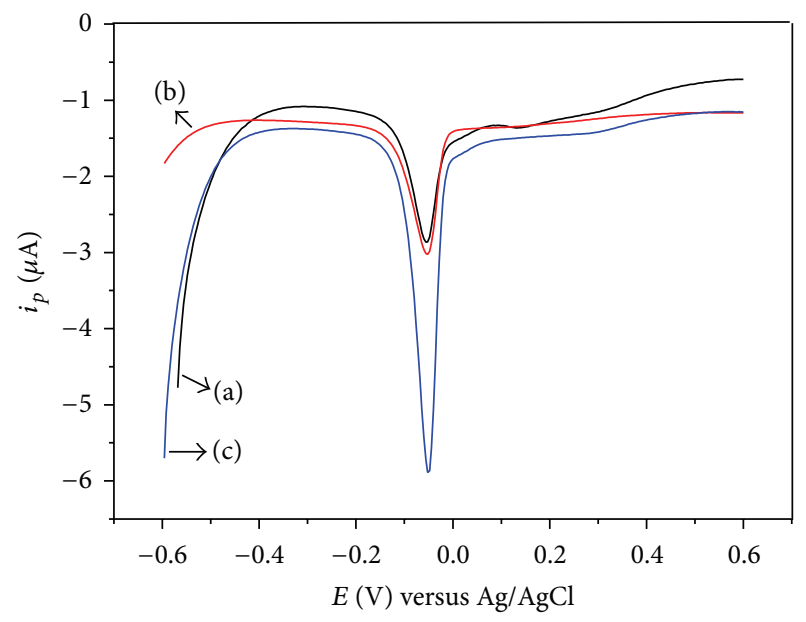

FIGURE 4: Differential pulse anodic stripping voltammetry of Cu (II) on GCE (a), GCE/PVB (b), and GCE/PRGNF (c). 


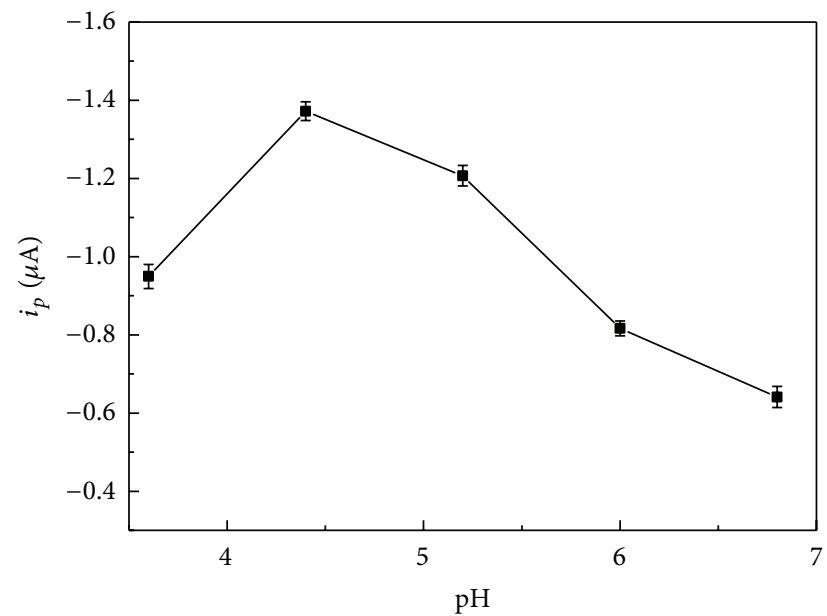

(a)

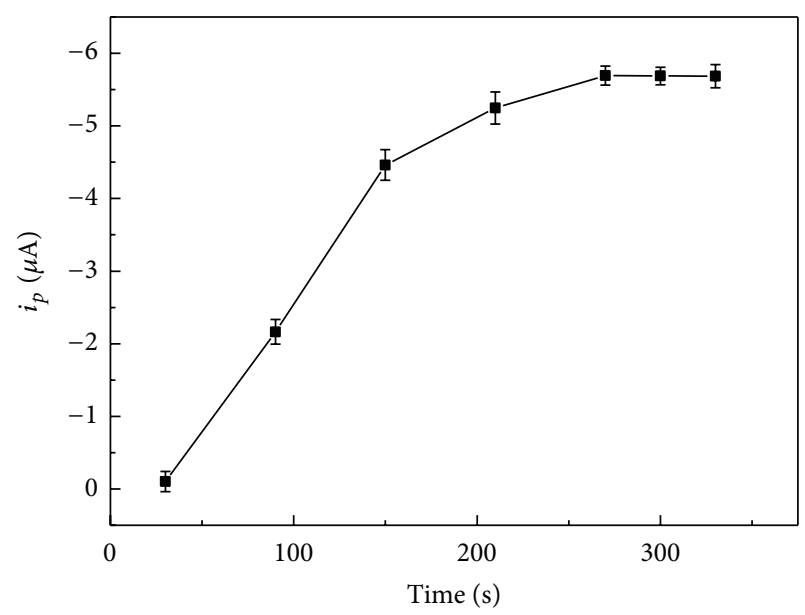

(c)

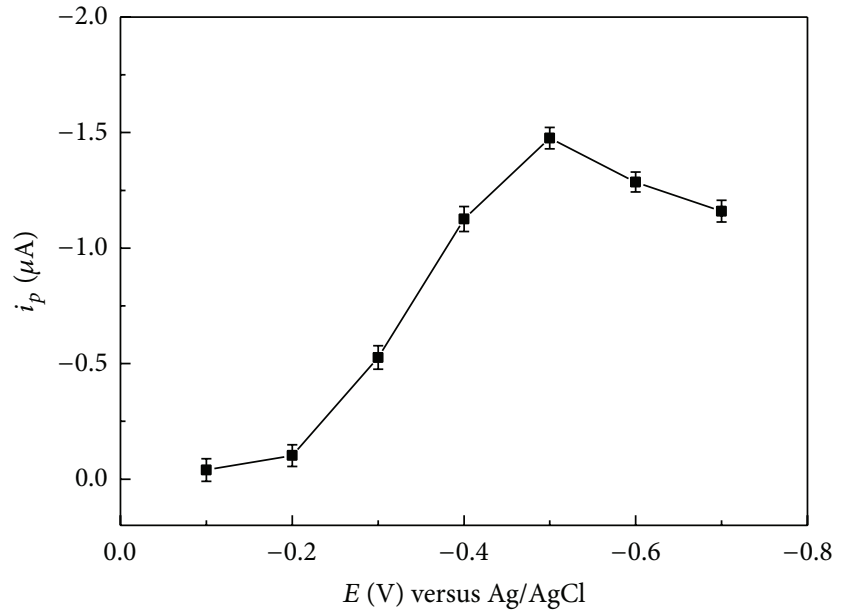

(b)

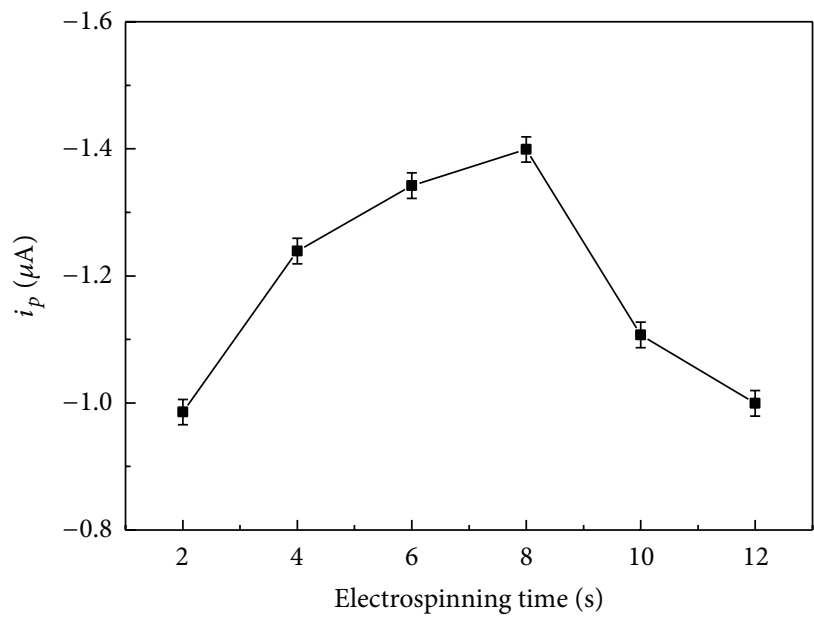

(d)

Figure 5: The effect of $\mathrm{pH}(\mathrm{a})$, accumulation potential (b), accumulation time (c), and electrospinning time (d) on the stripping peak currents of $6.0 \times 10^{-7} \mathrm{~mol} \cdot \mathrm{L}^{-1} \mathrm{Cu}$ (II).

3.5. Anti-Interference of GCE/PRGNF. In order to detect the identification performance of GCE/PRGNF, $6.0 \times$ $10^{-7} \mathrm{~mol} \cdot \mathrm{L}^{-1} \mathrm{Cu}$ (II) solutions coupled with different metal ions commonly present in natural water were used to research the anti-interference of GCE/PRGNF. The results were shown in Table 2. There was less than $\pm 5 \%$ of interference for GCE/PRGNF towards $\mathrm{Na}$ (I), K (I), Ca (II), Mg (II), Mn (II), Cd (II), and $\mathrm{Zn}$ (II), except $\mathrm{Pb}$ (II). The reason for the influence of $\mathrm{Pb}$ (II) is that the mixed layer formed on the surface of electrode in the process of the enrichment of $\mathrm{Pb}$ (II) and $\mathrm{Cu}$ (II), which changes the performance of the electrode. The interference of $\mathrm{Pb}$ (II) was about $5.1 \%$. Therefore, GCE/PRGNF was suitable for the determination of $\mathrm{Cu}$ (II) in real water samples with some pretreatments.

3.6. Detection of Cu (II) with GCE/PRGNF. Figure 6 showed the stripping voltammograms under optimized conditions with the concentration of $\mathrm{Cu}$ (II) from 0.06 to $2.2 \mu \mathrm{M}$ and the corresponding calibration curve of the stripping peak current versus the concentrations of $\mathrm{Cu}$ (II) (inset). The GCE/PRGNF showed good linear detection range from 0.06 to $2.2 \mu \mathrm{M}$ with a detection limit of $4.1 \mathrm{nM}(S / N=3)$ and a sensitivity of $103.51 \mu \mathrm{A} \cdot \mu \mathrm{M}^{-1} \cdot \mathrm{cm}^{-2}$. Compared with other nanomaterials modified electrodes $[11,12]$, PVB/RGO nanofibers modified GCE shows a low detection limit and a higher sensitivity.

\section{Conclusions}

Electrospinning technique was used to construct the hybrid nanofiber of GO and PVB. PVB/RGO nanofiber modified GCE was fabricated through electrochemical reduction of PVB/GO nanofiber modified GCE and applied for detection of $\mathrm{Cu}$ (II) in water. The PVB/RGO nanofibers modified GCE displays good analytical performance including wide linear range, low detection limit, high sensitivity, good repeatability, and anti-interference ability towards other metal ions. The composite of RGO into PVB nanofibers avoids the agglomerate of RGO and overcomes the defect of water-soluble 
TABLE 1: $i_{p}$ of the GCE/PRGNF responding to the $6.0 \times 10^{-7} \mathrm{~mol} \cdot \mathrm{L}^{-1} \mathrm{Cu}$ (II).

\begin{tabular}{lcccccccccc}
\hline$n$ & 1 & 2 & 3 & 4 & 5 & 6 & 7 & 8 & 9 & 10 \\
\hline $\begin{array}{l}i_{p} \\
(\mu \mathrm{A})\end{array}$ & 0.461 & 0.466 & 0.460 & 0.463 & 0.463 & 0.460 & 0.466 & 0.462 & 0.464 & 0.461 \\
\hline
\end{tabular}

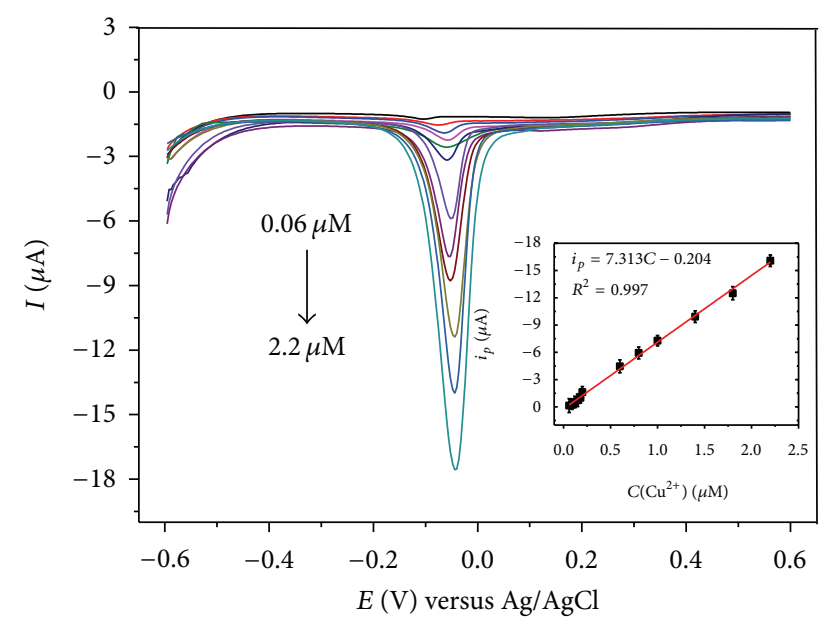

FIGURE 6: Differential pulse stripping voltammetry of GCE/PRGNF in $0.1 \mathrm{M} \mathrm{NaAc}-\mathrm{HAc}$ ( $\mathrm{pH} 4.4$ ) with various concentrations of $\mathrm{Cu}$ (II) (from $0.06 \sim 2.2 \mu \mathrm{M}$ ). Inset is the calibration curve of the stripping peak currents versus the concentrations of $\mathrm{Cu}$ (II).

TABLE 2: Anti-interference of GCE/PRGNF.

\begin{tabular}{lcc}
\hline Concentration $\left(\mathrm{mol} \cdot \mathrm{L}^{-1}\right)$ & Species & Interference $(\%)$ \\
\hline \multirow{3}{*}{$3.0 \times 10^{-4}$} & $\mathrm{Na}^{+}$ & -1.6 \\
& $\mathrm{~K}^{+}$ & -0.23 \\
& $\mathrm{Ca}^{2+}$ & -2.7 \\
& $\mathrm{Mg}^{2+}$ & +0.2 \\
\hline \multirow{2}{*}{$6.0 \times 10^{-5}$} & $\mathrm{Mn}^{2+}$ & -3.1 \\
& $\mathrm{Cd}^{2+}$ & -2.4 \\
\hline \multirow{2}{*}{$1.2 \times 10^{-5}$} & $\mathrm{~Pb}^{2+}$ & -5.1 \\
& $\mathrm{Zn}^{2+}$ & -3.2 \\
\hline
\end{tabular}

polymer electrospinning membrane unfitted for application under high-humidity environment. The fabricated sensor based on PVB/RGO nanofibers is promising in the determination of trace $\mathrm{Cu}$ (II) in real samples.

\section{Conflict of Interests}

The authors declare that there is no conflict of interests regarding the publication of this paper.

\section{Acknowledgment}

This work was financially supported by the National Natural Science Foundation of China (21207018).

\section{References}

[1] A. K. Singh, S. Mehtab, and A. K. Jain, "Selective electrochemical sensor for copper (II) ion based on chelating ionophores," Analytica Chimica Acta, vol. 575, no. 1, pp. 25-31, 2006.

[2] D. Citak and M. Tuzen, "A novel preconcentration procedure using cloud point extraction for determination of lead, cobalt and copper in water and food samples using flame atomic absorption spectrometry," Food and Chemical Toxicology, vol. 48, no. 5, pp. 1399-1404, 2010.

[3] X. Wen, Q. Yang, Z. Yan, and Q. Deng, "Determination of cadmium and copper in water and food samples by dispersive liquid-liquid microextraction combined with UV-vis spectrophotometry," Microchemical Journal, vol. 97, no. 2, pp. 249-254, 2011.

[4] J. S. Becker, M. V. Zoriy, C. Pickhardt, N. Palomero-Gallagher, and K. Zilles, "Imaging of copper, zinc, and other elements in thin section of human brain samples (hippocampus) by laser ablation inductively coupled plasma mass spectrometry," Analytical Chemistry, vol. 77, no. 10, pp. 3208-3216, 2005.

[5] N. S. Gadhari, B. J. Sanghavi, S. P. Karna, and A. K. Srivastava, "Potentiometric stripping analysis of bismuth based on carbon paste electrode modified with cryptand [2.2.1] and multiwalled carbon nanotubes," Electrochimica Acta, vol. 56, no. 2, pp. 627$635,2010$.

[6] S. Jahandari, M. A. Taher, H. Fazelirad, and I. Sheikhshoai, "Anodic stripping voltammetry of silver(I) using a carbon paste electrode modified with multi-walled carbon nanotubes," Microchimica Acta, vol. 180, no. 5-6, pp. 347-354, 2013.

[7] H. Khani, M. K. Rofouei, P. Arab, V. K. Gupta, and Z. Vafaei, "Multi-walled carbon nanotubes-ionic liquid-carbon paste electrode as a super selectivity sensor: application to potentiometric monitoring of mercury ion(II)," Journal of Hazardous Materials, vol. 183, no. 1-3, pp. 402-409, 2010.

[8] W. J. Yi, Y. Li, G. Ran, H. Q. Luo, and N. B. Li, "A glassy carbon electrode modified with antimony and poly(p-aminobenzene sulfonic acid) for sensing lead(II) by square wave anodic stripping voltammetry," Microchimica Acta, vol. 179, no. 1-2, pp. 171-177, 2012.

[9] M. B. Gholivand and A. A. Romiani, "Application of adsorptive stripping voltammetry to the simultaneous determination of bismuth and copper in the presence of nuclear fast red," Analytica Chimica Acta, vol. 571, no. 1, pp. 99-104, 2006.

[10] M. Moyo, J. O. Okonkwo, and N. M. Agyei, "Maize tasselmodified carbon paste electrode for voltammetric determination of $\mathrm{Cu}(\mathrm{II})$," Environmental Monitoring and Assessment, vol. 186, no. 8, pp. 4807-4817, 2014.

[11] B. C. Janegitz, L. H. Marcolino-Junior, S. P. Campana-Filho, R. C. Faria, and O. Fatibello-Filho, "Anodic stripping voltammetric determination of copper(II) using a functionalized carbon nanotubes paste electrode modified with crosslinked chitosan," Sensors and Actuators, B: Chemical, vol. 142, no. 1, pp. 260-266, 2009. 
[12] M. Lin, X. Hu, Z. Ma, and L. Chen, "Functionalized polypyrrole nanotube arrays as electrochemical biosensor for the determination of copper ions," Analytica Chimica Acta, vol. 746, pp. 6369, 2012.

[13] M. Pumera, A. Ambrosi, A. Bonanni, E. L. K. Chng, and H. L. Poh, "Graphene for electrochemical sensing and biosensing," TrAC-Trends in Analytical Chemistry, vol. 29, no. 9, pp. 954965, 2010.

[14] A. K. Geim and K. S. Novoselov, “The rise of graphene," Nature Materials, vol. 6, no. 3, pp. 183-191, 2007.

[15] S. Liu, X. Liu, Z. Li, S. Yang, and J. Wang, "Fabrication of freestanding graphene/polyaniline nanofibers composite paper via electrostatic adsorption for electrochemical supercapacitors," New Journal of Chemistry, vol. 35, no. 2, pp. 369-374, 2011.

[16] K. S. Novoselov, A. K. Geim, S. V. Morozov et al., "Electric field in atomically thin carbon films," Science, vol. 306, no. 5696, pp. 666-669, 2004.

[17] T. Mueller, F. Xia, and P. Avouris, "Graphene photodetectors for high-speed optical communications," Nature Photonics, vol. 4, no. 5, pp. 297-301, 2010.

[18] B. Y. Zhang, T. Liu, B. Meng et al., "Broadband high photoresponse from pure monolayer graphene photodetector," Nature Communications, vol. 4, article 1811, 2013.

[19] J. Ma, J. Zhang, Z. Xiong, Y. Yong, and X. S. Zhao, "Preparation, characterization and antibacterial properties of silver-modified graphene oxide," Journal of Materials Chemistry, vol. 21, no. 10, pp. 3350-3352, 2011.

[20] S. Liu, T. H. Zeng, M. Hofmann et al., "Antibacterial activity of graphite, graphite oxide, graphene oxide, and reduced graphene oxide: Membrane and oxidative stress," ACS Nano, vol. 5, no. 9, pp. 6971-6980, 2011.

[21] L. Qu, Y. Liu, J.-B. Baek, and L. Dai, “Nitrogen-doped graphene as efficient metal-free electrocatalyst for oxygen reduction in fuel cells," ACS Nano, vol. 4, no. 3, pp. 1321-1326, 2010.

[22] L. Zhang and Z. Xia, "Mechanisms of oxygen reduction reaction on nitrogen-doped graphene for fuel cells," The Journal of Physical Chemistry C, vol. 115, no. 22, pp. 11170-11176, 2011.

[23] F. Fu and Q. Wang, "Removal of heavy metal ions from wastewaters: a review," Journal of Environmental Management, vol. 92, no. 3, pp. 407-418, 2011.

[24] J. Hou, Z. Liu, and P. Zhang, "A new method for fabrication of graphene/polyaniline nanocomplex modified microbial fuel cell anodes," Journal of Power Sources, vol. 224, pp. 139-144, 2013.

[25] Y. Chang, G. Han, M. Li, and F. Gao, "Graphene-modified carbon fiber mats used to improve the activity and stability of Pt catalyst for methanol electrochemical oxidation," Carbon, vol. 49, no. 15, pp. 5158-5165, 2011.

[26] C. L. Scott, G. Zhao, and M. Pumera, "Stacked graphene nanofibers doped polypyrrole nanocomposites for electrochemical sensing," Electrochemistry Communications, vol. 12, no. 12, pp. 1788-1791, 2010.

[27] Y. Ke, F. Zhu, F. Zeng, T. Luan, C. Su, and G. Ouyang, "Preparation of graphene-coated solid-phase microextraction fiber and its application on organochlorine pesticides determination," Journal of Chromatography A, vol. 1300, pp. 187-192, 2013.

[28] G. Yang, J. Cao, L. Li, R. K. Rana, and J.-J. Zhu, "Carboxymethyl chitosan-functionalized graphene for label-free electrochemical cytosensing," Carbon, vol. 51, no. 1, pp. 124-133, 2013.

[29] Y. Wei, C. Gao, F.-L. Meng et al., " $\mathrm{SnO}_{2} /$ reduced graphene oxide nanocomposite for the simultaneous electrochemical detection of cadmium(II), lead(II), copper(II), and mercury(II): an interesting favorable mutual interference," The Journal of Physical Chemistry C, vol. 116, no. 1, pp. 1034-1041, 2012.

[30] Z. Peining, A. S. Nair, P. Shengjie, Y. Shengyuan, and S. Ramakrishna, "Facile fabrication of $\mathrm{TiO}_{2}$-graphene composite with enhanced photovoltaic and photocatalytic properties by electrospinning," ACS Applied Materials and Interfaces, vol. 4, no. 2, pp. 581-585, 2012.

[31] E. Llobet, "Gas sensors using carbon nanomaterials: a review," Sensors and Actuators, B: Chemical, vol. 179, pp. 32-45, 2013.

[32] Q. Wu, C. Feng, G. Zhao, C. Wang, and Z. Wang, "Graphenecoated fiber for solid-phase microextraction of triazine herbicides in water samples," Journal of Separation Science, vol. 35, no. 2, pp. 193-199, 2012.

[33] J. Li, D. Kuang, Y. Feng, F. Zhang, Z. Xu, and M. Liu, "A graphene oxide-based electrochemical sensor for sensitive determination of 4-nitrophenol," Journal of Hazardous Materials, vol. 201-202, pp. 250-259, 2012.

[34] Y. Zhang, Y. Wang, J. Jia, and J. Wang, "Nonenzymatic glucose sensor based on graphene oxide and electrospun $\mathrm{NiO}$ nanofibers," Sensors and Actuators B: Chemical, vol. 171-172, pp. 580-587, 2012.

[35] A. Ahmadalinezhad and A. Chen, "Nanomaterial-based electrochemical biosensors," in Nanomedical Device and Systems Design: Challenges, Possibilities, Visions, p. 339, CRC Press, New York, NY, USA, 2013.

[36] Q. Guo, J. Huang, P. Chen, Y. Liu, H. Hou, and T. You, "Simultaneous determination of catechol and hydroquinone using electrospun carbon nanofibers modified electrode," Sensors and Actuators B: Chemical, vol. 163, no. 1, pp. 179-185, 2012. 

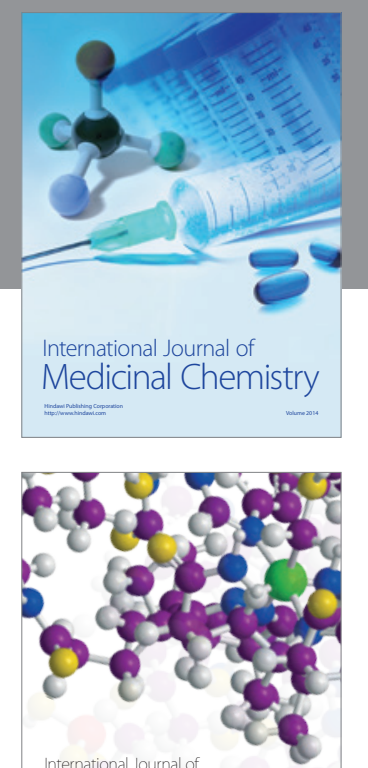

\section{Carbohydrate} Chemistry

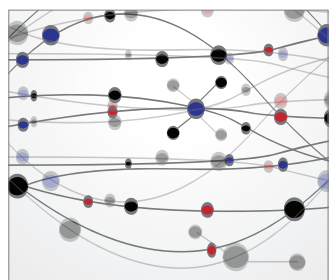

The Scientific World Journal
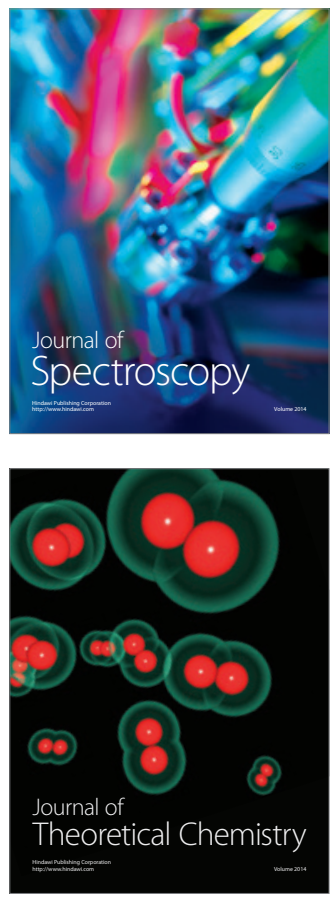
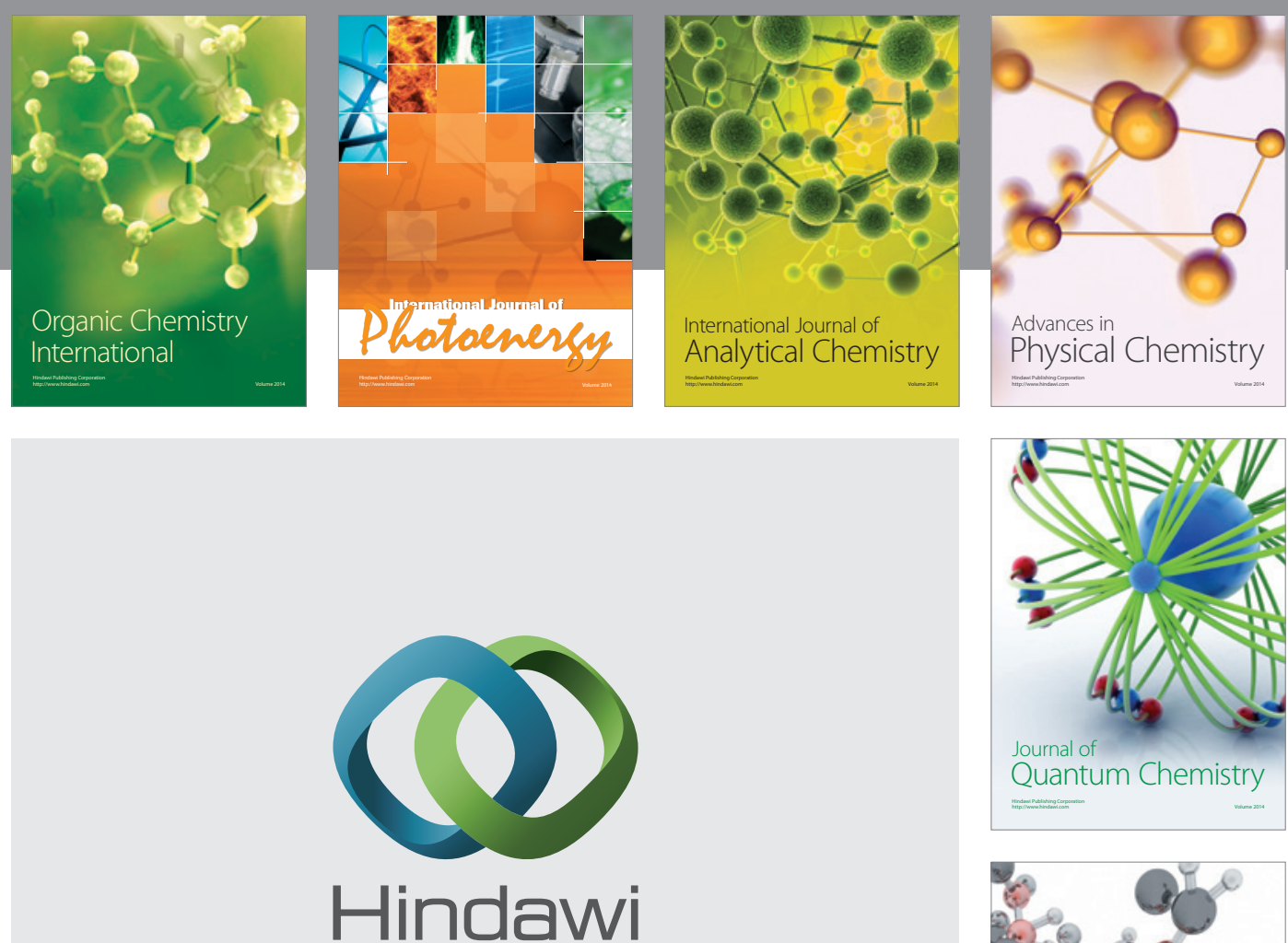

Submit your manuscripts at

http://www.hindawi.com

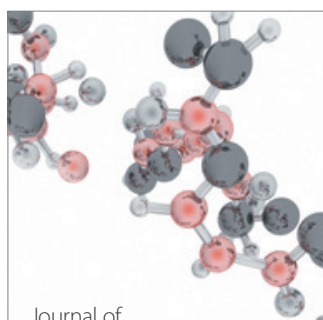

Analytical Methods

in Chemistry

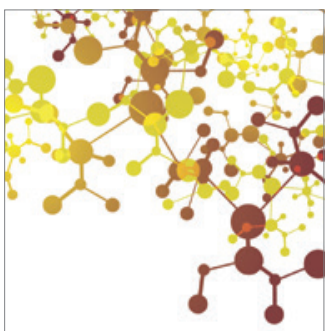

Journal of

Applied Chemistry

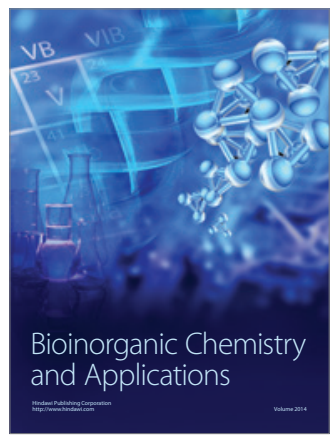

Inorganic Chemistry
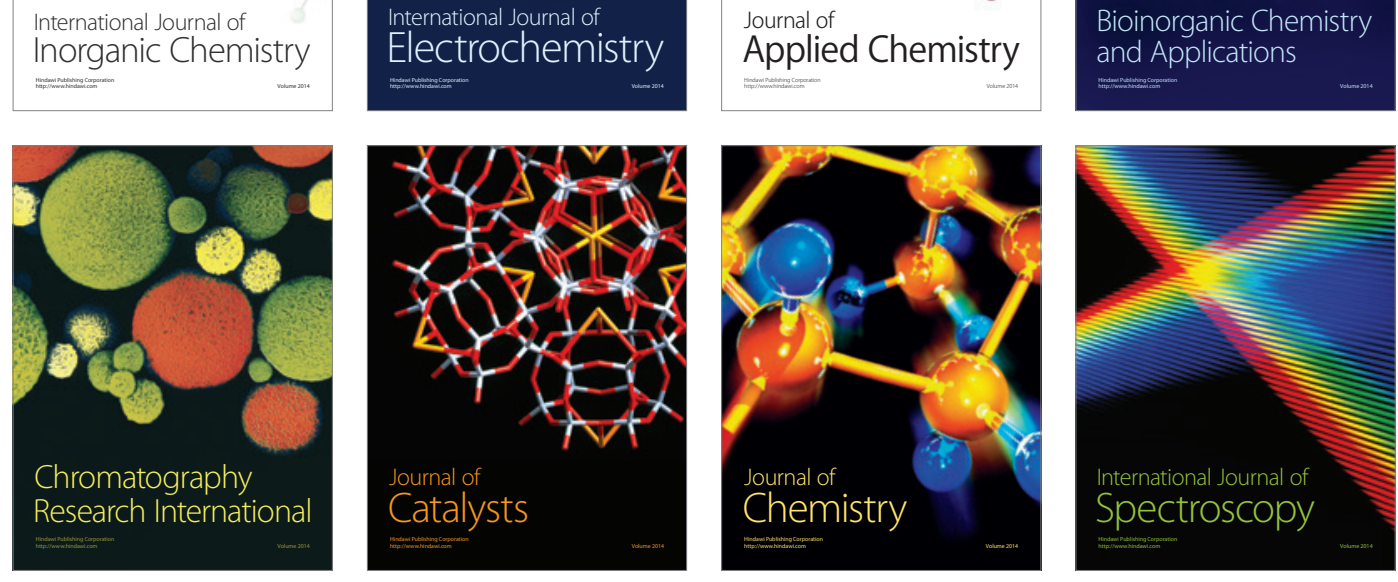